\title{
El poder de la tecnología inteligente sofisticada
}

\section{doi: $10.52749 /$ fh.v2i3.8}

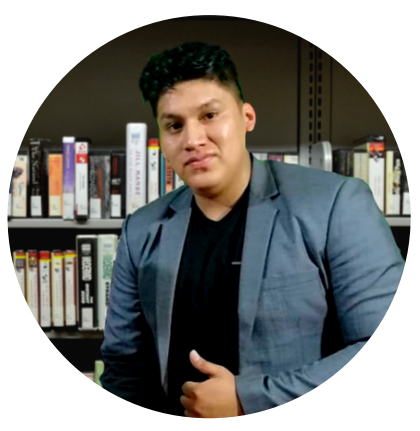

\section{KENNER MORI CASTRO}

https://orcid.org/0000-0002-4749-9166

CEO y cofundador de Innovacit, fundador de la organización social Cultura Steam, divulgador de ciencia, tecnología y educación. Miembro del Consejo Regional de Ciencia, tecnología, emprendimiento e innovación de Huánuco (CORCITEI). Miembro Investigador del Instituto de Estudios Transhumanistas (IET). Formó parte del Consejo Regional de la Juventud - Huánuco. Lic. en Sociología por la Universidad Nacional Hermilio Valdizán, cursa estudios de Maestría en Gestión Pública para el Desarrollo Social e Ingeniería de Sistemas computacionales.

kenner.yesser@gmail.com

O) @kennermori19

Resumen. Este artículo tiene por objetivo analizar dos capítulos de la serie de ciencia ficción "Black Mirror" de la empresa Netflix Inc. Donde en ambos se utilizan tecnología inteligente muy sofisticada. Uno de los capítulos de la serie lleva por título "Vuelvo enseguida" y se encuentra en la Temporada 2 y el otro se ubica en la Temporada 3 con el título "Odio Nacional". Vuelvo en seguida, trata de una joven pareja que se va a vivir a una casa de campo, sin embargo, el novio Ash fallece con una camioneta y su novia Martha triste por la soledad accede a tener conversaciones con una Inteligencia Artificial que tiene todos los rasgos de su novio fallecido, ahí empieza la trama principal. Por otro lado, el capítulo de Odio Nacional, trata de una serie de asesinatos que es investigado por 4 detectives, donde se concluye que los drones autónomos IDA, tienen cierta responsabilidad en ello. En ambos capítulos se muestra los peligros de la tecnología.

Palabras clave: black mirror, Netflix, robótica, tecnología inteligente

La gran mayoría de nosotros tiene la oportunidad de ver en este siglo el nacimiento de tecnologías que son logros grandiosos de la ingeniería, como drones autónomos, robots que imitan la morfología de algunos animales, las impresiones 3D, la Inteligencia Artificial - IA, la ingeniería genética y otras tecnologías disruptivas que tienen protagonismo en este artículo.

Para llevarlos a contexto se va a comentar y a analizar dos capítulos de la serie de ciencia ficción "Black Mirror" escrito por Charlie Brooker de la empresa Netflix Inc. Uno de ellos lleva por título "Vuelvo enseguida" (2013) y el otro "Odio Nacional" (2016).

\section{Vuelvo enseguida}

Este capítulo, en resumen, nos muestra el desarrollo e interacción con una Inteligencia Artificial más sofisticada y con grandes avances. Martha y Ash son una joven pareja que se muda a una casa de campo. El capítulo inicia con la muerte de Ash en un accidente de carretera tras conducir de vuelta la camioneta usada para la mudanza.

Aquí empieza la trama principal. Tras la muerte de su novio, y para no sentir la soledad o el dolor de perder a su compañero sentimental, Martha acepta mantener comunicación con un software o IA que accede a toda la información sobre su novio fallecido (publicaciones en línea, actualizaciones de Facebook, tweets y otro contenido público) e interactúa como él mediante el correo electrónico y llamadas, en un comienzo.

Con el tiempo Martha muestra desesperación y confusión. En una ocasión, deja caer su celular y rompe en llanto porque siente que dañó a su "novio", dicho de otro modo, empieza a tener sentimientos hacia un software que habla y "piensa" como él. De hecho, esto no está tan lejos de la realidad, Akihiko Kondo se enamoró de Hatsune Miku, un holograma conocida como la primera "Idol" virtual japonesa, con quien contrajo matrimonio el 04 de noviembre de 2018. Akihiko cuenta su historia y lo difícil que es lidiar con la aceptación de su familia. No obstante, lo más interesante es que la empresa Gatebox, que creó al holograma, realizó toda una campaña para ofrecer certificados de matrimonio con Hatsune Miku llegando a obtener 3 708 personas que solicitaron uno (Jiménez De la Fuente, 2019). ¿3708 personas quieren casarse con un holograma? 
Otro caso real es el de Zheng Jiajia un ingeniero chino de 31 años, experto en Inteligencia Artificial, que se casó con una mujer robot llamada Yingying construida por él mismo debido a que no encontraba una esposa humana (Molins , 2017).

Para no desviarnos de la trama, luego del ataque de pánico de Martha, ella se entera de que existe un nuevo servicio en etapa experimental que permite depositar la conciencia del Ash-virtual en un cuerpo biónico fabricado con carne sintética. Sería un androide con toda la configuración mental que tenía su novio. En la vida real, la empresa Boston Dynamics ya cuenta con robots cuadrúpedos y bípedos como Atlas, el cual es un robot humanoide con movimientos muy calculados. Aún sigue en investigación y en proceso de mejora de detalles, pero lo logrado hasta ahora es grandioso. Asimismo, se han desarrollado robots humanoides como Sofía, la cual fue construida por la empresa Hanson Robotics, tiene rostro humano y mantiene conversaciones como si fuera una persona mediante las herramientas en "inteligencia artificial" que le permiten simular personalidades humanas. A pesar de este avance singular, algunos expertos opinan que se trata de un "chatbot", como es el caso del ingeniero en informática Carlos Santana Vega (Santana, 2018). Un dato curioso de esta robot es que en el 2017 se volvió una ciudadana saudita y recibió incluso más derechos que las propias mujeres de ese país (BBC, 2017). ¿Cuán cerca estamos de tener androides con quienes cenar en casa? ¿Cuán cerca estamos de presentar a nuestra familia a un androide muy sofisticado como nuestra novia o novio? Estoy seguro de que en un futuro las relaciones sentimentales o sexuales de androides y humanos no serán tan extrañas como ahora, no obstante, eso no quita el hecho de preguntarnos si es un asunto moralmente correcto, ya sea por temas de salud mental, por ejemplo, o porque en nuestra sociedad ese acto sería poco aceptado e iría contra las creencias de muchas personas.

Volviendo al capítulo de la serie, en una escena Martha y Ash tienen relaciones sexuales. Ella queda sumamente sorprendida porque Ash puede durar el tiempo que ella desee y además ajustar el tamaño de su órgano viril para "complacerla más". En la actualidad existen los llamados "Sexbots" o "Sex Robots" que son desarrollados por varias compañías, uno de los robots más famosos es "Harmony" un robot humanoide con cuerpo de mujer creada por la empresa RealBotix que cuenta con inteligencia artificial para mantener conversaciones, se sincroniza con nuestro Smartphone u ordenador mediante una aplicación, donde podemos configurar a nuestro robot y su personalidad. Por otro lado, está "Henry", un robot sexual de apariencia masculina que tiene la misma función que Ash en cuanto al órgano viril masculino (Gurrier, 2021).

Los robots sexuales ya son tema de análisis de muchas personas y profesionales, si bien cada persona puede vivir su sexualidad con responsabilidad, no es descabellado pensar en que puede existir una empresa que desarrolle estos Sexbots con rostros y cuerpos de niños o niñas reforzando los casos de pedofilia, o, también, que cuentes con la capacidad de decidir qué rostro tiene tu robot sexual: el de tu actriz favorita, de tu vecina o de tu ex-enamorada.

¿Cómo garantizar que los robots sexuales son seguros? ¿Cuán ético sería mantener relaciones sexuales con un robot con aspecto de un infante? ¿De qué manera afectará a nuestro cerebro humano la intimidad con un robot sexual? Este capítulo de la serie de Netflix nos deja mucho por analizar y más aún en la parte final, donde se retrata una escena en la que años más tarde Martha cría a su hija de siete años, pero mantiene al androide Ash escondido en la buhardilla de su casa de campo, mostrándonos que aún mantiene un vínculo afectivo fuerte con el androide que tiene el aspecto de su novio fallecido. Luego de este capítulo no puedo evitar preguntarme ¿Cuán reales serían los sentimientos hacia un androide? ¿Cuánto influye el aspecto psicológico para mantener relaciones no solo sexuales sino sentimentales con un robot u holograma? ¿Si existieran en un futuro relaciones sentimentales de humanos con androides cómo sería la reproducción natural humana?

\section{Odio nacional}

Sobre este capítulo, la breve descripción que se brinda en Netflix dice lo siguiente: Dos detectives encuentran una pista inquietante tras la muerte de una periodista afectada por un escándalo en las redes sociales.

El capítulo inicia con la muerte de tres personas conocidas en circunstancias extrañas. Luego de la muerte de la periodista Jo Powers, quien fue atacada en las redes sociales tras publicar un artículo en el que criticó la inmolación de una activista con discapacidad, se siguen otras dos. La del Rapero 
Tusk, quien fue criticado por insultar y burlarse de un niño admirador suyo que lo imitó, y la de la joven Clara M. que publicó una fotografía donde fingía orinar en un monumento memorial a los fallecidos en la guerra.

Estos tres personajes son criticados en las redes sociales y los mensajes están acompañados del uso del hashtag "\#DeathTo...." seguido de su nombre. Esto conlleva a que las personas con mayor cantidad de hashtags sean asesinadas. Este detalle nos invita a apreciar el gran alcance que las redes sociales tienen para llegar al odio en masa e, indirectamente, crear cómplices de asesinato. Al final se descubre que las muertes son causadas por Drones Autónomos (IDA), que tienen la forma y tamaño de una abeja, los cuales entraron en funcionamiento tras la desaparición y extinción de las abejas reales en Inglaterra. Debido a la gran labor que tienen estos insectos en el medio ambiente para la polinización de las distintas plantas estos drones cumplen con esa función haciendo uso de pequeños paneles solares y replicándose en colmenas que son como "Impresoras 3D" más sofisticadas. Un dato interesante es que existen proyectos científicos similares a los IDA en la vida real. Uno de ellos es desarrollado en el Instituto Avanzado de Ciencia y Tecnología Industrial, AIST (Japón). Actualmente, los científicos Xi Yang y Eijiro Miyako (2020) trabajan en la creación de drones-abeja que reparten burbujas de jabón cargadas de polen con el fin de coadyuvar a la no disminución de esta especie por la degradación de su hábitat y el cambio climático.

Continuando con la trama, luego de estos homicidios la investigación concluye que la causa principal es el Hackeo de los IDA. Con los códigos correctos y el uso de visión artificial para el reconocimiento facial, Ios IDA se vuelven armas letales y poco sospechosas. Al final se descubre que el mismo gobierno tiene injerencia en esta última funcionalidad de los IDA, así como en el proyecto en general. Lo grandioso de este capítulo es que la creación de estos drones ayudó al planeta a cumplir la función de las abejas luego de su extinción; sin embargo, no toda tecnología es segura y por más que la encriptación sea de nivel "militar" como el de Ios IDA, hubo quienes lograron hackearla y utilizarla para dañar a las personas que tenían más menciones con el hashtag "\#DeathTo..." en la red social. ¿Se imaginan que por impopularidad o críticas sobre tu comportamiento se haga tendencia un asesinato?

Este capítulo pone en debate que incluso cuando se desarrolle la tecnología "más segura" que parezca inofensiva, aún es desarrollada por el hombre e incluso con ambiciones de algunos gobiernos por tener la tecnología militar más avanzada. En la serie se habla de abejas drones y en la vida real hablamos de todo tipo de armamento tecnológico avanzado, pero basta con revisar los últimos avances en tecnología para esbozar que nos encaminamos hacia el desarrollo de una serie de tecnologías descritas en películas de ciencia ficción del ayer que se asoman como la ciencia real de hoy. ¿Cómo serían las guerras en el futuro? ¿Realmente las tecnologías armamentistas que posee cada país son seguras ante todo hackeo? ¿Cuáles serán las nuevas armas tecnológicas?

Aún existen muchas preguntas por responder sobre el futuro de la "Tecnología Inteligente" y su impacto en nuestra sociedad y nuestras vidas, pero lo seguro es que las películas o series de ciencia ficción han tenido gran importancia para que muchas empresas, gobiernos, científicos o investigadores puedan adoptar la ficción y transformarla en realidad.

\section{Bibliografía}

BBC Mundo Tecnología. (30 de octubre de 2017). Sophia, la robot que tiene más derechos que las mujeres en Arabia Saudita. BBC News Mundo. https://www.bbc.com/mundo/noticias-41803576

Gurrier, M. (04 de Junio de 2021). El futuro del sexo tiene cara de robot. Forbes Argentina.

https://www.forbesargentina.com/lifestyle/el-futuro-sexo-tienecara-robot-n5966 
Jiménez De la Fuente , F. ( 28 de mayo de 2019). "Me casé con un holograma: es difícil de entender, pero debería ser respetado". BBC News - Mundo. https://www.bbc.com/mundo/noticiasinternacional-48229491

Molins Renter, A. (04 de abril de 2017). Un ingeniero chino crea una mujer robot y se casa con ella. La Vanguardia.

https://www.lavanguardia.com/vida/20170404/421432384087/ ingeniero-chino-mujer-robot.html

Santana, C. (Productor). (2018). El Robot Sophia ¿Progreso o fraude? | DotCSV [Video]. Youtube.

https://www.youtube.com/watch?v=Clz1uaAamLs
Xi, Y., \& Eijiro, M. (2020). Soap Bubble Pollination. iScience, 23(6). http://dx.doi.org/10.1016/j.isci.2020.101188

Brooker, C. (Escritor), \& Harris, O. (Director). (21 de octubre del 2016). Odio Nacional (Temporada 3, Episodio 6) [Episodio de serie]. En Brooker, C. (Productor), Black Mirror. Netflix.

Brooker, C. (Escritor), \& Harris, O. (Director). (11 de febrero del 2013). Vuelvo enseguida (Temporada 2, Episodio 1) [Episodio de serie]. En Brooker, C. (Productor), Black Mirror. Netflix.

\section{Cómo citar este artículo:}

Mori, K. (2021). El poder de la tecnología inteligente sofisticada. Futuro Hoy, 2(3), 44-47. https://doi.org/10.52749/fh.v2i3.8

Esta obra está bajo licencia internacional Creative Commons 4.0 Reconocimiento 4.0. 